\title{
PORTFOLIO ROBUSTNESS EVALUATION: A CASE STUDY IN THE ELECTRICITY SECTOR
}

\author{
João Carlos LOURENÇO, João Oliveira SOARES, Carlos A. BANA E COSTA \\ CEG-IST, Instituto Superior Técnico, Universidade de Lisboa, Av. Rovisco Pais, 1, \\ 1049-001 Lisbon, Portugal
}

Received 16 November 2012; accepted 29 December 2013

\begin{abstract}
Managers continually face the task of allocating resources to projects when there is not enough money to fund them all. Portfolio Robustness Evaluation (PROBE) is a multicriteria decision support system developed to help managers to perform that difficult task. This paper presents a PROBE model, developed for an electricity distribution company, to select the best portfolio of projects, subject to budget constraints for different types of projects and various organisational units in multiple time periods. Projects requiring large-scale investments are analysed separately from the small-scale projects. The robustness of the selected portfolio of large-scale projects is analysed in an iterative process where broader uncertainty ranges are considered for the values of the projects, and also when an environmental impact criterion is added to the evaluation model.
\end{abstract}

Keywords: portfolio decision analysis, portfolio robustness evaluation, resource allocation, multicriteria analysis, electricity sector.

JEL Classification: C61, D81, G11, G31, L94.

\section{Introduction}

The scope of portfolio selection, given its widest interpretation, is extraordinarily broad (Salo et al. 2011b). In this paper, the focus is directed at real assets and at capital budgeting, more precisely at the efficient allocation of financial resources to indivisible investment projects and its enhancement with modern portfolio decision analysis tools (Salo et al. 2011a).

The use of linear programming in capital budgeting has been suggested since the mid 1950s (Gunther 1955; Lorie, Savage 1955; Markowitz, Manne 1957; Asher 1962). Companies and organisations faced with a number of investment projects that exceed their available

Corresponding author João Carlos Lourenço

E-mail: joao.lourenco@tecnico.ulisboa.pt 
resources, in general, aim at finding the subset of projects (the portfolio) that maximizes the value created. Assuming that projects are indivisible, the problem leads to a binary mathematical programming formulation subject to a budget constraint (the knapsack problem Kleinmuntz 2007), which can be extended, when appropriate, with several other types of linear constraints. Interdependencies among projects may also lead to non-linear objective functions (Dickinson et al. 2001) and the formulation can also accommodate multiple objectives (see, e.g., Golabi 1987; Ringuest, Graves 1990; Stummer, Heidenberger 2003; Ewing et al. 2006; for a more global overview of multicriteria methods used in economics see Zavadskas, Turskis 2011, and in the electricity sector see Atici, Ulucan 2011 and Ertay et al. 2013).

The selection of multiple projects under scarcity of resources may also be made by means of a prioritisation approach. Projects are prioritised by their benefit-to-cost ratios and selected until the available budget is exceeded (Edwards 1977; Sharpe, Keelin 1998; Buede, Bresnick 2007; Phillips, Bana e Costa 2007). This approach is appealing in the context of strategic decision-aiding processes, as it permits straightforward interaction with the decision-makers; however, it is not so suitable for handling programming and multi-period constraints. This is the case of the portfolio decision analysis presented in this paper and developed for EDPD (EDP Distribuição - Energia, S.A.), the main distributor of electricity in Portugal.

The paper analyses the heuristic prioritisation procedure used by EDPD's managers and presents an alternative modelling of the problem using the PROBE (Portfolio Robustness Evaluation) decision support system (Lourenço et al. 2012). PROBE enables several types of linear constraints to be considered and, given the costs and benefits of the projects, identifies all convex and non-convex efficient portfolios. It also permits the robustness of a chosen portfolio to be analysed, given uncertainty ranges on project benefits, by searching for competitor portfolios that may provide more overall benefits without increasing the total cost. An alternative approach for sensitivity analysis on benefits' uncertainties can be found in Beaujon et al. (2001).

The robustness analysis implemented in PROBE allows performing an a posteriori sensitivity analysis on several inputs simultaneously, which was a missing feature in the commercial packages for multicriteria resource allocation analysed in Lourenço et al. (2008). The non-commercial software RPM-Decisions (http://www.rpm.tkk.fi/rpm-software.html) implements the "Robust Portfolio Modeling" (RPM) approach (Liesiö et al. 2007, 2008), which follows a different path. Contrary to PROBE, the robustness analysis provided by RPM is not concerned with analyzing the stability of a portfolio. Instead, it reverses the expost sensitivity analysis perspective, by incorporating uncertainty a priori as "incomplete information" in the formulation of the problem and looking for non-dominated portfolios (Lourenço et al. 2012). In RPM "loose preference statements and wide score intervals typically result in a large number of non-dominated portfolios" (Liesiö et al. 2008: 682). The decision-maker is then invited to narrow the initial uncertainty domain, therefore reducing the number of non-dominated portfolios, and decision rules can be applied to eventually select one non-dominated portfolio. In contrast, PROBE supposes the decision-maker can use best-guess parameter values to find an attractive proposed portfolio, and then offers a form of robustness analysis in which the proposed portfolio is compared to competitors in its neighbourhood (Lourenço et al. 2012). Liesiö and Salo (2012) developed an approach similar 
to RPM for portfolio selection in problems where a decision-maker faces incomplete information about scenario probabilities and risk preferences. However, given that in the EDPD case there are no probabilities associated with the uncertain parameters, we do not discuss this approach further. A different approach consists in selecting "robust" projects, i.e. the projects more often included in optimal portfolios obtained by using different combinations of the uncertain parameters (Bryan 2010).

Fasth and Larsson (2013) apply "interval contractions" to iteratively reduce the uncertainty (defined under the form of intervals) upon the benefits and the costs of the projects. In an a priori approach, Fasth and Larsson (2013) find one minimax optimal portfolio at each step (e.g. by contracting the intervals by $20 \%$ ) until reaching point values for the parameters of the projects. Then, they analyse in how many portfolios the projects were included. The projects not included in any portfolio, or included in all portfolios, are not analysed further, being discarded, or selected, respectively. The projects that are included in some but not all of the portfolios are further analysed using an a posteriori analysis. One variant of the a posteriori approach consists in stepwise contracting the intervals of the parameters of the model and in each step calculating the minimum and maximum difference in expected benefit between two portfolios until a dominance relationship appears (see other variants in Fasth, Larsson 2013). However, contrary to RPM and PROBE, Fasth and Larsson's (2013) approach pairwise compares all portfolios, which may result in an unrealistic number of combinations to handle for a large number of projects.

The remainder of this paper is organised as follows. Section 1 introduces the EDPD problem and discusses the drawbacks of the project selection procedure in use at the company. Section 2 develops the alternative PROBE model. There is a budget for projects requiring large-scale investments and another budget for small-scale projects. Therefore, each type of projects is subject to a separate portfolio decision analysis with PROBE. Robustness analysis is focused on the optimal portfolio of large-scale projects, in an iterative process where broader uncertainty ranges are considered for the values of the projects. EDPD has been using only one selection criterion, the maximization of $N P V$, but the company has also other concerns, namely the environmental impacts of large-scale projects. Section 3 shows the extent to which the introduction in the model of an additional evaluation criterion, allowing to take into account the environmental impacts of the projects, would affect the stability of the selected portfolio. The last Section presents some final remarks.

\section{The EDPD project selection problem and procedure}

EDP S.A. is the largest industrial group in Portugal and a leader in the energy sector, spreading its activities across several countries in Europe and America. EDPD is the EDP distributor of electricity in mainland Portugal. Each year, EDPD chooses a portfolio of projects among several hundred indivisible projects, each one requiring investment for one to three years, which in total by far exceeds the available budget. There are large-scale projects (e.g. new electric power substations) and small-scale ones (e.g. new low-voltage power lines) from six organisational units, which correspond to six geographical zones, Z1 to Z6. EDPD limits largescale investments to $75 \%$ of each year's budget. This paper analyses the investment decision 
taken by EDPD for the first of three years. Budgetary data are detailed in Table 1, including data related to commitments with ongoing projects and compulsory investments in the period that should be deducted before proceeding with the resource allocation. There are 372 new projects in the first year; 28 are large-scale ones, with an average cost of $€ 2463.36 \times 10^{3}$ whereas the average cost of the small-scale ones is only $€ 1893 \times 10^{3}$. Financing all the projects would not be possible because their total cost $\left(€ 75487.44 \times 10^{3}\right)$ exceeds the total amount available $\left(€ 48.552 \times 10^{3}\right)$ for funding new projects during the period.

Table 1. EDPD’s budget (in $€ 10^{3}$ )

\begin{tabular}{ccccc}
\hline & Year 1 & Year 2 & Year 3 & Total \\
\hline (a) Total budget & 20000 & 20000 & 20000 & 60000 \\
\hline For large-scale projects & 15000 & 15000 & 15000 & 45000 \\
\hline For small-scale projects & 5000 & 5000 & 5000 & 15000 \\
\hline (b) Ongoing investments & 6359 & 4451 & 0 & 10810 \\
\hline On large-scale projects & 6234 & 4451 & 0 & 10685 \\
\hline On small-scale projects & 125 & 0 & 0 & 125 \\
\hline (c) Compulsory investment (on small-scale projects) & 552 & 86 & 0 & 638 \\
\hline (d) = (a) - (b) - (c) Available budget for new projects & 13089 & 15463 & 20000 & 48552 \\
\hline For new large-scale projects & 8766 & 10549 & 15000 & 34315 \\
\hline For new small-scale projects & 4323 & 4914 & 5000 & 14237 \\
\hline Generic & 2500 & 4914 & 5000 & 12414 \\
\hline Zone Z1 & 255 & & & \\
\hline Zone Z2 & 296 & & & \\
\hline Zone Z3 & 387 & & & \\
\hline Zone Z4 & 70 & & & \\
\hline Zone Z5 & 281 & & & \\
\hline Zone Z6 & 534 & & & \\
\hline
\end{tabular}

Let $c_{j}, P V_{j}$ and $N P V_{j}\left(=P V_{j}-c_{j}\right)$ be the investment cost, present value and net present value of the candidate project $j(j=1, \ldots, n)$, respectively. The selection procedure used by EDPD can be described by the following six prioritisation steps: (i) List the candidate projects; (ii) Determine the value of the profitability index (or benefit-to-cost ratio) for each project $j$ by $N P V_{j} / c_{j}$ (or $P V_{j} / c_{j}$, which will not alter the prioritisation because $\left.P V_{j} / c_{j}=N P V_{j} / c_{j}+1\right)$; (iii) Order the projects from most to least profitability; (iv) Go down the list, choosing projects as long as there are available financial resources for each one of the two types of projects, in each one of the six zones and in each one of the three years; (v) When at least one of these budget constraints cannot be satisfied, discard the project under consideration; (vi) Repeat steps (iv) and (v) until all budgets are simultaneously satisfied.

Unfortunately, this prioritisation procedure does not always select the portfolio of projects that maximizes total NPV. Section 2.1 shows that this drawback is due to the fact that the prioritisation procedure ignores non-convex efficient portfolios and proposes overcoming this problem by using mathematical programming. 


\section{An alternative approach to the EDPD problem}

\subsection{Introducing PROBE to EDPD's managers}

Our first suggestion to the EDPD's managers was to split the resource allocation into two sequential problems, focusing firstly on the large-scale projects only, as recommended for other similar resource allocation contexts with projects of significantly different costs (Kleinmuntz, Kleinmuntz 1999). Let us then consider the 28 large-scale projects. Given the global budget available for this type of projects $\left(€ 34315 \times 10^{3}\right.$ ), and ignoring for now all other budgetary constraints, the prioritisation approach selects the first 14 projects in Table 2 , with a cumulative cost of $€ 30065.55 \times 10^{3}$ and a cumulative $N P V$ of $€ 84759.33 \times 10^{3}$. Alternatively, one can find the optimal solution to the knapsack problem (1), where $B$ represents the available budget.

Table 2. Prioritisation of the large-scale projects (in $€ 10^{3}$ )

\begin{tabular}{|c|c|c|c|c|c|c|}
\hline $\begin{array}{c}\text { Priority } \\
\text { order }\end{array}$ & Project & $N P V$ & Cost & $N P V /$ Cost & $\begin{array}{c}\text { Cumulative } \\
N P V\end{array}$ & $\begin{array}{c}\text { Cumulative } \\
\text { Cost }\end{array}$ \\
\hline 1 & P10 & 12016.67 & 602.38 & 19.95 & 12016.67 & 602.38 \\
\hline 2 & P16 & 9741.32 & 700.00 & 13.92 & 21757.99 & 1302.38 \\
\hline 3 & P15 & 11447.06 & 2023.48 & 5.66 & 33205.05 & 3325.86 \\
\hline 4 & P17 & 9741.32 & 1773.83 & 5.49 & 42946.37 & 5099.69 \\
\hline 5 & $\mathrm{P} 23$ & 3896.55 & 1436.11 & 2.71 & 46842.92 & 6535.80 \\
\hline 6 & P05 & 11411.82 & 5221.40 & 2.19 & 58254.74 & 11757.20 \\
\hline 7 & $\mathrm{P} 03$ & 7511.86 & 3683.78 & 2.04 & 65766.60 & 15440.98 \\
\hline 8 & P18 & 5971.11 & 3144.54 & 1.90 & 71737.71 & 18585.52 \\
\hline 9 & P19 & 8181.24 & 5375.40 & 1.52 & 79918.95 & 23960.92 \\
\hline 10 & P14 & 411.00 & 306.82 & 1.34 & 80329.95 & 24267.74 \\
\hline 11 & P11 & 220.43 & 174.57 & 1.26 & 80550.38 & 24442.31 \\
\hline 12 & $\mathrm{P} 02$ & 148.97 & 126.00 & 1.18 & 80699.35 & 24568.31 \\
\hline 13 & P13 & 1735.00 & 2112.67 & 0.82 & 82434.35 & 26680.98 \\
\hline 14 & P06 & 2324.98 & 3384.57 & 0.69 & 84759.33 & 30065.55 \\
\hline 15 & P04 & 2993.71 & 4964.12 & 0.60 & 87753.04 & 35029.67 \\
\hline 16 & P07 & 1467.35 & 3528.12 & 0.42 & 89220.39 & 38557.79 \\
\hline 17 & P09 & 732.40 & 1788.49 & 0.41 & 89952.79 & 40346.28 \\
\hline 18 & P01 & 232.61 & 587.13 & 0.40 & 90185.40 & 40933.41 \\
\hline 19 & P12 & 487.14 & 1318.71 & 0.37 & 90672.54 & 42252.12 \\
\hline 20 & P28 & 508.86 & 1550.00 & 0.33 & 91181.40 & 43802.12 \\
\hline 21 & P08 & 549.83 & 2902.53 & 0.19 & 91731.23 & 46704.65 \\
\hline 22 & P21 & 466.13 & 2482.62 & 0.19 & 92197.36 & 49187.27 \\
\hline 23 & P22 & 535.50 & 3084.23 & 0.17 & 92732.86 & 52271.50 \\
\hline 24 & P27 & 898.95 & 6229.88 & 0.14 & 93631.81 & 58501.38 \\
\hline 25 & P25 & 124 & 1199.68 & 0.00 & 93633.05 & 59701.06 \\
\hline 26 & P26 & 128 & 1914.76 & 0.00 & 93634.33 & 61615.82 \\
\hline 27 & $\mathrm{P} 24$ & 100 & 3452.94 & 0.00 & 93635.33 & 65068.76 \\
\hline 28 & P20 & 046 & 3905.33 & 0.00 & 93635.79 & 68974.09 \\
\hline
\end{tabular}


Maximize

$$
\sum_{j=1}^{28} N P V_{j} x_{j}
$$

subject to:

$$
\begin{gathered}
\sum_{j=1}^{28} c_{j} x_{j} \leq B, \\
x_{j} \in\{0,1\}, \quad j=1, \ldots, 28,
\end{gathered}
$$

with $x_{j}=1$ if project $j$ is included in the optimal portfolio and $x_{j}=0$ otherwise.

Although not highlighted in Lourenço et al. (2012), PROBE tests if there are other optimal solutions and identifies the one with minimal cost by solving problem (2):

Minimize

subject to:

$$
\sum_{j=1}^{28} c_{j} x_{j}
$$

$$
\begin{gathered}
\sum_{j=1}^{28} N P V_{j} x_{j}=v^{p}, \\
x_{j} \in\{0,1\}, \quad j=1, \ldots, 28,
\end{gathered}
$$

where $v^{p}$ is the $N P V$ of the optimal portfolio $p$, being $p$ the optimal solution of problem (1).

Note also that, contrary to using the prioritisation procedure, the efficient solution found could be different if $P V_{j}$ was used instead of $N P V_{j}$ (Dantzig 1957) and could result in a lower total $N P V$.

The optimal (and efficient) portfolio for EDPD is formed by 15 projects and is better than the prioritisation portfolio in $€ 1745.85 \times 10^{3}$ and costs more $€ 4170.16 \times 10^{3}$. The first 13 projects in Table 2 are common to both portfolios, which differ only because project P06 is replaced by projects $\mathrm{P} 04$ and P12.

The graph in Figure 1 is a display of the PROBE decision support system that presents all the efficient portfolios when the budget $(B)$ varies from zero to the sum of the costs of all large-scale projects. In Figure 1 the convex-efficient portfolios, which correspond to those selected by a prioritisation procedure based on the ratio $N P V /$ cost, are shown in light gray and are linked with a dotted line.

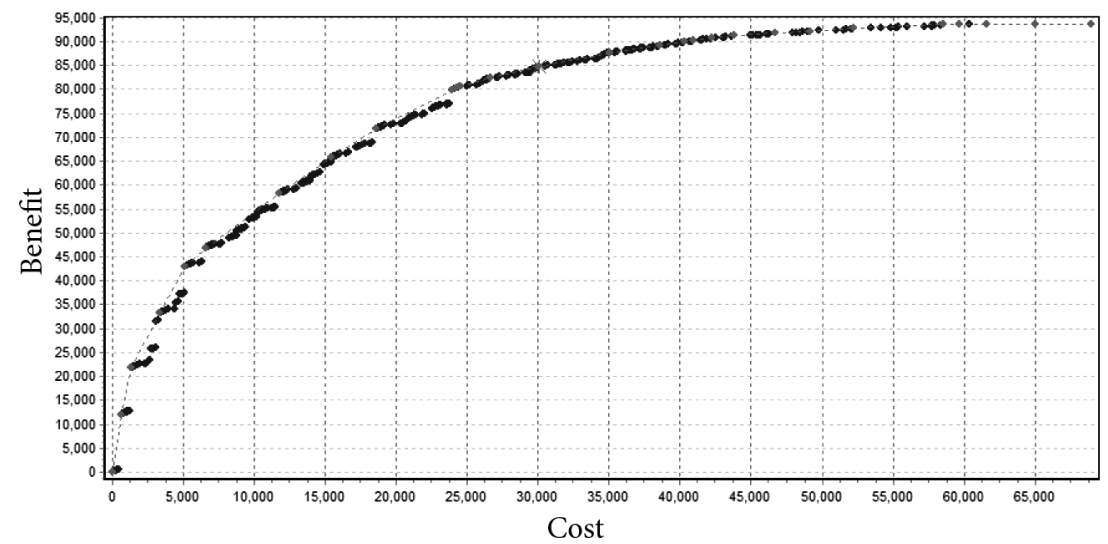

Fig. 1. PROBE display of the efficient frontier (in $€ 10^{3}$ ) 
The graph in Figure 2 is a zoom of the portion of the graph in Figure 1 between the portfolio chosen by prioritisation (A) and the next convex efficient portfolio (C), showing 22 (non-convex) efficient portfolios that exhibit, without exceeding the budget, higher total $N P V$ than portfolio A. The best of them is portfolio B, signalled with a star dot in Figure 2, which is the optimal solution to problem (2).

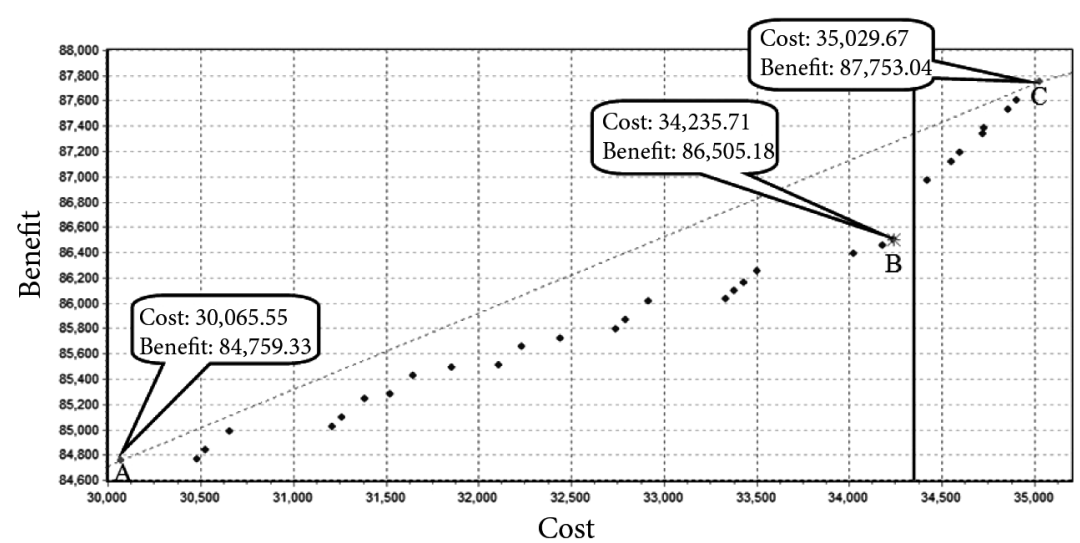

Fig. 2. Zoom of efficient frontier between the convex efficient portfolio chosen by prioritisation (A) and the next convex efficient portfolio (C).

The optimal portfolio (B) is signalled with a star dot and the vertical line indicates the available budget (in $€ 10^{3}$ )

When presented with the graph in Figure 2, the head of the EDPD Department of Network Planning noted it makes evident that portfolio B not only offers a better use of the budget than the prioritisation choice A, but also it implies a smaller additional investment to get the benefit of portfolio $C$. This is related to the usual separation between hard and soft budgetary constraints (hard and soft capital rationing) done in financial literature (see, e.g., Brealey, Myers 2003: 108-109). Budgetary constraints are considered to be soft if it is possible for a company or a department to expand its budgetary limits in the presence of profitable investment projects, financing their activities through the capital markets or the banking system. However, after the 2008 financial crisis the credit limits are in several cases very tight.

\subsection{Finding the best portfolio of large-scale projects with multi-period budget constraints}

Having introduced the PROBE mathematical programming approach to the EDPD investment problem, it is now interesting to use it to highlight the benefit of having discarded the three annual-budget constraints. For this purpose, one first needs to solve the following new maximization problem (3), which results from problem (1) by replacing the global budget constraint with the three annual-budget constraints, where $c_{j y}$ is the cost of large-scale project $j$ on year $y(y=1, \ldots, 3)$. 
Maximize:

subject to:

$$
\sum_{j=1}^{28} N P V_{j} x_{j}
$$

$$
\begin{gathered}
\sum_{j=1}^{28} c_{j 1} x_{j} \leq 8,766, \sum_{j=1}^{28} c_{j 2} x_{j} \leq 10,549, \sum_{j=1}^{28} c_{j 3} x_{j} \leq 15,000, \\
x_{j} \in\{0,1\}, \quad j=1, \ldots, 28 .
\end{gathered}
$$

Subsequently, problem (4) must be solved to find the least costly portfolio that meets the constraints of problem (3) and provides the same $N P V\left(v^{p}\right)$ as the optimal portfolio $p$ previously found.

Minimize:

subject to:

$$
\sum_{j=1}^{28} c_{j} x_{j}
$$

$$
\begin{gathered}
\sum_{j=1}^{28} c_{j 1} x_{j} \leq 8,766, \sum_{j=1}^{28} c_{j 2} x_{j} \leq 10,549, \sum_{j=1}^{28} c_{j 3} x_{j} \leq 15,000, \\
\sum_{j=1}^{28} N P V_{j} x_{j}=v p, \\
x_{j} \in\{0,1\}, \quad j=1, \ldots, 28 .
\end{gathered}
$$

Portfolio B, found in Section 2.1, requires investments in the first two years that exceed the available budgets (respectively, $€ 6985.77 \times 10^{3}$ and $€ 1621.7 \times 10^{3}$ ). Therefore, portfolio $\mathrm{B}$ is not a feasible solution to the EDPD problem. The optimal solution is now portfolio $\mathrm{O}$ (formed by 11 projects: P10, P16, P15, P17, P23, P05, P03, P18, P19, P01 and P28) which offers less $6.8 \%\left(€ 5844.76 \times 10^{3}\right.$ ) of total $N P V$ than portfolio $\mathrm{B}$. This is the consequence of imposing rigid annual budgets. Indeed, as highlighted by Lorie and Savage (1955: 233), "the imposition of additional restrictions upon the freedom of action of any agency can obviously never increase the value of the best opportunity available to that agency".

\subsection{Portfolio robustness evaluation}

Different methods can lead to different estimates of the benefits of the projects, as remarked by Beaujon et al. (2001). Therefore, it is important to explore the consequences for portfolio selection of having those uncertain estimates. The EDPD investment problem is affected by the uncertainty of the expected cash flows of the projects, namely, the uncertainty of their $P V$ values. The core feature of PROBE is the ability to evaluate the robustness of the selected portfolio considering several sources of uncertainty simultaneously. Since the investment in large-scale projects can absorb $75 \%$ of the total budget, it is wise to analyse the extent to which the choice of the optimal portfolio O, found in Section 2.2, is robust.

In the particular case of a single benefit criterion, like the $N P V$, we define robustness as follows. Let us denote by $p$ the optimal portfolio with total benefit $v^{p}=\sum_{j \in p} v_{j}$, where $v_{j}$ indicates the benefit value of project $j$, and total cost $c^{p}=\sum_{j \in p} c_{j}$, and by $d$ another portfolio with $v^{d}=\sum_{j \in d} v_{j}$ and $c^{d}=\sum_{j \in d} c_{j}$. Suppose that the benefits of $p$ and $d$ are affected 
by uncertainty within $\underline{v}^{p} \leq v^{p} \leq \bar{v} p$ and $\underline{v}^{d} \leq v^{d} \leq \bar{v}^{d}$, respectively, where $\underline{v}^{p}=\sum_{j \in p} \underline{v}_{j}$, $\bar{v} p=\sum_{j \in p} \bar{v}_{j}, \underline{v}^{d}=\sum_{j \in d} \underline{v}_{j}, \bar{v}^{d}=\sum_{j \in d} \bar{v}_{j}$ and $\underline{v}_{j} \leq v_{j} \leq \bar{v}_{j}$ for all $j$. Portfolio $d$ is a competitor of the optimal portfolio $p$ if, and only if, (i) $\sum_{j \in d \backslash p} \underline{c}_{j} \leq \sum_{j \in p \backslash d} \bar{c}_{j}$ and (ii) there exists a combination of feasible project benefit values such that $\sum_{j \in p \backslash d} v_{j}-\sum_{j \in d \backslash p} v_{j}<0$. The choice of portfolio $p$ will undoubtedly be robust when $p$ has no competitors. (Portfolio robustness evaluation in problems with multiple benefit criteria requires a different definition, which is presented in Lourenço et al. 2012).

In the EDPD case the decision support system PROBE was used to evaluate the robustness of portfolio $\mathrm{O}$ for variations of $\pm \alpha \%(1 \leq \alpha \leq 20$, increasing $1 \%$ at each iteration) affecting the $P V$ of each project, simultaneously. There is no competitor for a level of uncertainty $\alpha \leq 5 \%$. Table 3 shows that the first competitor portfolio appears for $\alpha=6 \%$ and the number of competitors rises until nine for $\alpha=20 \%$.

Table 3. Differences between portfolio O and its competitors

\begin{tabular}{llll}
\hline $\begin{array}{c}\text { Detected for the first } \\
\text { time when... }\end{array}$ & $\begin{array}{c}\text { Number of com- } \\
\text { petitor portfolios }\end{array}$ & $\begin{array}{c}\text { Projects exclusive to } \\
\text { the optimal portfolio }\end{array}$ & $\begin{array}{c}\text { Projects exclusive to the } \\
\text { new competitor portfolio }\end{array}$ \\
\hline$\alpha=6 \%$ & 1 & P28 & P02, P11 \\
\hline$\alpha=11 \%$ & 2 & P01, P28 & P02, P11 \\
\hline$\alpha=12 \%$ & 3 & P28 & P11 \\
\hline$\alpha=16 \%$ & 5 & P01, P28 & P11 \\
\cline { 2 - 4 } & \multirow{2}{*}{$\alpha=19 \%$} & P28 & P02 \\
\hline$\alpha=20 \%$ & 7 & P01, P28 & P02 \\
\hline
\end{tabular}

The differences in the large-scale projects that compose portfolio $\mathrm{O}$ and its competitors are also shown in Table 3. It can be observed that: when $\alpha=6 \%$ there is only one competitor portfolio, which includes projects P02 and P11 instead of project P28; and when $\alpha=11 \%$ there are two competitor portfolios, one detected for the first time when $\alpha=6 \%$ and a new one that includes P02 and P11 instead of projects P01 and P28.

Table 4 shows that most of the projects that form portfolio $\mathrm{O}$ also belong to the competitor portfolios, for example, $91 \%$ of the projects are kept with $\alpha=10 \%$, and $73 \%$ when $\alpha=20 \%$, which indicates a significant level of stability.

Table 4. Analysis of the stability of portfolio O

\begin{tabular}{ccc}
\hline Uncertainty on the $P V$ & No. of stable projects & Percentage of stable projects \\
\hline $1 \% \leq \alpha \leq 5 \%$ & 11 & 100 \\
\hline $6 \% \leq \alpha \leq 10 \%$ & 10 & 91 \\
\hline $11 \% \leq \alpha \leq 18 \%$ & 9 & 82 \\
\hline $19 \% \leq \alpha \leq 20 \%$ & 8 & 73 \\
\hline
\end{tabular}


Another relevant analysis is the regret evaluation. For an optimal portfolio $p$ and a competitor portfolio $d$, the maximal regret (i.e. loss) in NPV caused by selecting $p$ instead of $d$ corresponds to the absolute value of $\sum_{j \in p \backslash d} \underline{v}_{j}-\sum_{j \in d \backslash p} \bar{v}_{j}$. For $k$ competitors (with $k>1$ ) the maximal regret of selecting $p$ corresponds to the maximum of the $k$ maximal (pairwise) regrets. Figures 3 and 4 show, in absolute and relative terms, the maximal regret in the overall $N P V$ of portfolio $\mathrm{O}$, for different levels of uncertainty. It can be observed in Figure 4 that the maximal regret in $N P V$ for $\alpha=6 \%$ represents only $0.03 \%$ of the minimum $N P V$ of portfolio O; for $\alpha=20 \%$ the maximal regret in $N P V$ is $€ 406.3 \times 10^{3}$, which is only $0.69 \%$ of the minimum NPV of portfolio O. These small potential losses were considered irrelevant by EDPD's managers and confirmed the robustness of selecting portfolio $\mathrm{O}$.

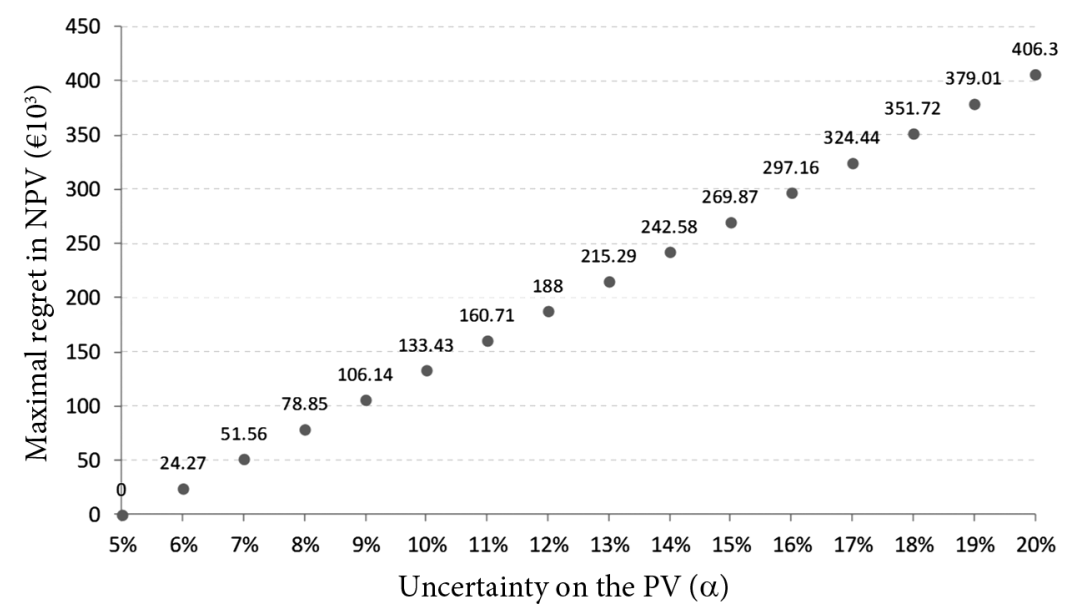

Fig. 3. Uncertainty on the $P V$ vs. maximal regret in $N P V$

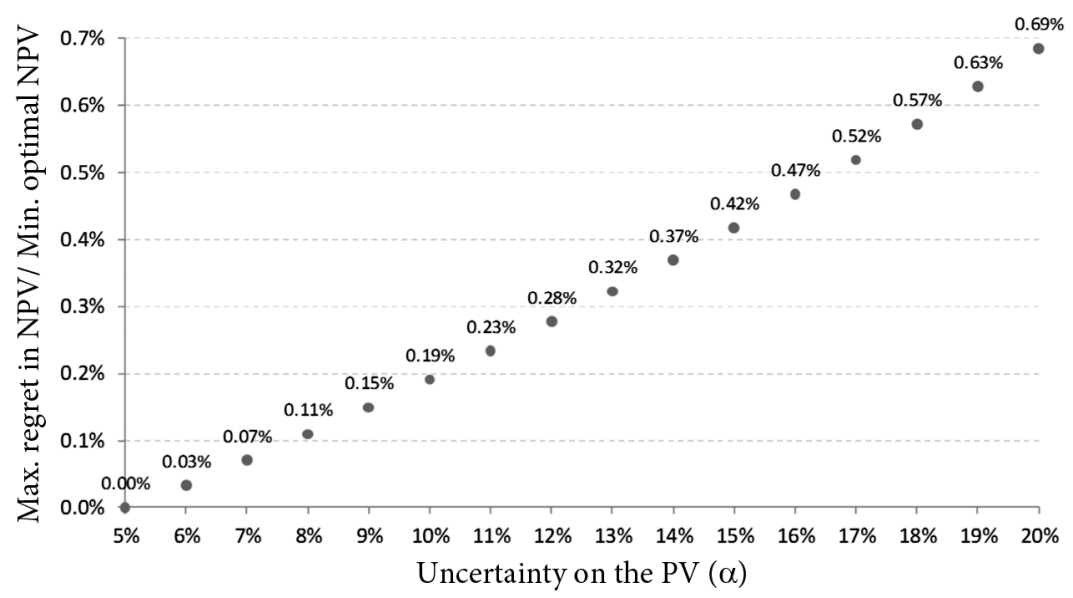

Fig. 4. Uncertainty on the $P V$ vs. max. regret in $N P V / \min$. $N P V$ of portfolio $\mathrm{O}$ 


\subsection{Finding the best portfolio of small-scale projects}

Let us now turn the analysis to the 344 small-scale projects and look for the best portfolio under the three annual-budget constraints and the six zone constraints concerning the first year of investment (the data for the 344 small-scale projects is presented in the Appendix, Table 6). The optimal portfolio found by solving problem (5) includes 265 projects, which cost $€ 4637.09 \times 10^{3}$ and provide a total NPV of $€ 23554.7 \times 10^{3}$.

Maximize:

subject to:

$$
\sum_{j=1}^{344} N P V_{j} x_{j}
$$

$$
\begin{gathered}
\sum_{j=1}^{344} c_{j 1} x_{j} \leq 4,323, \sum_{j=1}^{344} c_{j 2} x_{j} \leq 4,914, \sum_{j=1}^{344} c_{j 3} x_{j} \leq 5,000, \\
\sum_{j \in \mathrm{Z} 1} c_{j 1} x_{j} \geq 255, \sum_{j \in \mathrm{Z} 2} c_{j 1} x_{j} \geq 296, \\
\sum_{j \in \mathrm{Z} 3} c_{j 1} x_{j} \geq 387, \sum_{j \in \mathrm{Z} 4} c_{j 1} x_{j} \geq 70, \\
\sum_{j \in \mathrm{Z} 5} c_{j 1} x_{j} \geq 281, \sum_{j \in \mathrm{Z} 6} c_{j 1} x_{j} \geq 534, \\
x_{j} \in\{0,1\}, \quad j=1, \ldots, 344,
\end{gathered}
$$

where: $c_{j y}$ is the investment cost of project $j$ in year $y(y=1, \ldots, 3), Z n$ denotes the subset of small-scale projects that belong to zone $n(n=1, \ldots, 6), x_{j}=1$ if the small-scale project $j$ is included in the optimal portfolio and $x_{j}=0$ otherwise.

The optimal solution of problem (5) is confirmed to be also efficient by solving problem (6). Minimize:

$$
\sum_{j=1}^{344} c_{j} x_{j}
$$

subject to:

$$
\begin{gathered}
\sum_{j=1}^{344} c_{j 1} x_{j} \leq 4,323, \sum_{j=1}^{344} c_{j 2} x_{j} \leq 4,914, \sum_{j=1}^{344} c_{j 3} x_{j} \leq 5,000, \\
\sum_{j \in \mathrm{Z} 1} c_{j 1} x_{j} \geq 255, \sum_{j \in \mathrm{Z} 2} c_{j 1} x_{j} \geq 296, \\
\sum_{j \in \mathrm{Z} 3} c_{j 1} x_{j} \geq 387, \sum_{j \in \mathrm{Z} 4} c_{j 1} x_{j} \geq 70, \\
\sum_{j \in \mathrm{Z} 5} c_{j 1} x_{j} \geq 281, \sum_{j \in \mathrm{Z} 6} c_{j 1} x_{j} \geq 534, \\
\sum_{j=1}^{344} N P V_{j} x_{j}=23,554.7 \\
x_{j} \in\{0,1\}, \quad j=1, \ldots, 344 .
\end{gathered}
$$

Note that the constraint with the budget limit on year 3 is not active in problems (5) and (6), because the 344 small-scale projects do not have investment costs in that year. However, we opted to keep that constraint in these formulations to clearly express the concern expressed by EDPD's managers. 


\subsection{Comparing the results of the two approaches}

Table 5 presents the results of portfolio decision analyses of the EDPD problem done with the PROBE mathematical programming formulation and the EDPD prioritisation procedure. The portfolio found with the former provides a global NPV greater than that of the latter in $€ 421.53 \times 10^{3}$, for an investment cost greater in $€ 1915.09 \times 10^{3}$ and closer to the budget. Most of that additional benefit is due to large-scale projects, precisely $€ 372.07 \times 10^{3}$, for an additional investment of $€ 1836.56 \times 10^{3}$.

Table 5. Benefits and costs of the solutions found (in $€ 10^{3}$ )

\begin{tabular}{|c|c|c|c|c|c|}
\hline \multirow{2}{*}{ Type of project / Approach } & \multirow{2}{*}{$N P V$} & \multicolumn{4}{|c|}{ Costs } \\
\hline & & Year 1 & Year 2 & Year 3 & Total \\
\hline \multicolumn{6}{|l|}{ Large-scale projects } \\
\hline $\begin{array}{l}\text { (a) Budget for new large } \\
\text { projects }\end{array}$ & & 8766.00 & 10549.00 & 15000.00 & 34315.00 \\
\hline (b) PROBE portfolio & 80660.42 & 8741.63 & 9828.18 & 7528.24 & 26098.05 \\
\hline (c) EDPD portfolio & 80288.35 & 8684.56 & 9273.69 & 6303.24 & 24261.49 \\
\hline$(d)=(b)-(c)$ & 372.07 & 57.07 & 554.49 & 1.225 & 1836.56 \\
\hline \multicolumn{6}{|l|}{ Small-scale projects } \\
\hline $\begin{array}{l}\text { (e)Budget for new small } \\
\text { projects }\end{array}$ & & 4323.00 & 4914.00 & 5000.00 & 14237.00 \\
\hline (f) PROBE portfolio & 23554.70 & 4322.76 & 314.33 & 0 & 4637.09 \\
\hline (g) EDPD portfolio & 23505.24 & 4320.58 & 237.98 & 0 & 4558.56 \\
\hline$(\mathrm{h})=(\mathrm{f})-(\mathrm{g})$ & 49.46 & 2.18 & 76.35 & 0 & 78.53 \\
\hline \multicolumn{6}{|l|}{ Total } \\
\hline $\begin{array}{l}\text { (i) Budget for new } \\
\text { projects }\end{array}$ & & 13089.00 & 15463.00 & 20000.00 & 48552.00 \\
\hline (j) PROBE portfolio & 104215.10 & 13064.39 & 10142.51 & 7528.24 & 30735.10 \\
\hline (k) EDPD portfolio & 103793.60 & 13005.14 & 9511.67 & 6303.24 & 28820.10 \\
\hline$(\mathrm{l})=(\mathrm{l})-(\mathrm{k})$ & 421.53 & 59.25 & 630.84 & 1225.00 & 1915.09 \\
\hline
\end{tabular}

\section{Multicriteria portfolio analysis of the effect of adding an environmental impact criterion}

As mentioned in the introduction, and detailed in Lourenço et al. (2012), the PROBE decision support system allows a multicriteria portfolio decision analysis to be performed (Salo et al. 2011a). This was used to take into consideration EDPD's concern with the environmental impacts (EI) of large-scale projects, and to observe the extent to which the stability of the portfolio of large-scale projects that maximizes profitability, found in Section 2.2, would be affected by an increasing importance given to minimizing environmental impacts as well. For this purpose, two evaluation criteria, NPV and EI, were considered and, within a valid range of the latter, it was assumed that EDPD decision-makers' preferences would be such that (i) the company would be willing to accept trading off less 
$N P V$ with less $E I$, and vice versa, and (ii) $N P V$ and $E I$ are additive independent (Keeney, Raiffa 1993). Under these compensatory working hypotheses, an additive value model, defined as follows (7), was built:

$$
V_{j}=k_{1} v_{1}\left(N P V_{j}\right)+k_{2} v_{2}\left(E I_{j}\right) \text { with } k_{1}>0, k_{2}>0 \text { and } k_{1}+k_{2}=1 \text {, }
$$

where: $V_{j}$ is the overall value of large-scale project $j ; k_{1}$ and $k_{2}$ are the scaling constants ("relative weights") of the $N P V$ and $E I$ criteria, respectively; and $v_{1}\left(N P V_{j}\right)$ and $v_{2}\left(E I_{j}\right)$ are the partial value scores of project $j$ calculated by the respective value functions - built in such a way that the overall value of the "do nothing" project, i.e., a project with $€ 0$ of NPV and no EI, should result equal to 0 (Clemen, Smith 2009; Morton 2010). The value function over $N P V$ was assumed to be linear and was anchored on $v_{1}(€ 0)=0$ and $v_{1}\left(€ 6000 \times 10^{3}\right)=100$. In this exploratory multicriteria analysis, the EDPD's environmental manager first considered four plausible scenarios of increasing environmental impact, ranging from "the project has no significant environmental impact (No EI)" to "the project has significant impact in a protected area (EI ---)" (see Fig. 5a). Then, the MACBETH method (Bana e Costa et al. 2012) was applied to build a value function for the EI criterion. For this purpose, the EDPD's manager judged the difference in attractiveness between each two of the four EI scenarios, shown in the MACBETH judgements matrix of Figure 5b. For example, the difference in attractiveness between "No EI" and "EI -" was judged as moderate, whereas the difference between "No EI" and "EI --" was judged as strong.

The project has...

... no significant environmental impact

... significant noise or visual impact

(No EI)

... significant noise and visual impact

... significant impact in a protected area

(a)

\begin{tabular}{|c|c|c|c|c|c|}
\hline \multicolumn{5}{|c|}{ Environmental impacts (EI) } & $x$ \\
\hline 䀳 & NoEl & El. & $\mathrm{El} \cdots$ & EI... & $\begin{array}{l}\text { Current } \\
\text { scale }\end{array}$ \\
\hline No El & no & moderate & strong & v. strong & 0.0 \\
\hline $\mathrm{El} \cdot$ & & no & weak & strong & -37.5 \\
\hline EI.. & & & no & moderate & -62.5 \\
\hline EI $\cdots$ & & & & no & -100.0 \\
\hline \multicolumn{6}{|c|}{ Consistent judgements } \\
\hline
\end{tabular}

(b)

Fig. 5. Environmental impact criterion: (a) descriptor of performance and

(b) MACBETH matrix of judgements and value function

The "current scale" column in Figure 5b shows the proposed value scale that was generated by MACBETH, using the linear programming problem described by Bana e Costa et al. (2005), which was validated by the EDPD's environmental manager. (The NPV scores, EI scores and annual costs of the large-scale projects are presented in the Appendix, Table 7).

Under these modelling conditions, and with $V_{j}$ replacing $N P V_{j}$ in (3) and (4), the first project to leave the portfolio previously selected would be P01, when $k_{2}$ is raised to $5.9 \%$, which means that an $N P V$ of $€ 232.61 \times 10^{3}$ would not be enough to compensate a significant noise and visual impact. 


\section{Conclusions}

This paper describes a case study in the domain of capital budgeting involving different types of projects and budget constraints in multiple time periods. Two approaches for project portfolio selection were discussed: a heuristic prioritisation procedure followed by the electricity distribution company EDPD, which proved to be suboptimal, and the alternative PROBE approach based on 0-1 linear programming. Large-scale and small-scale projects were analysed separately, for there is a fixed budget for each type. The uncertainty involving the expected cash flows of the large-scale projects was also analysed in terms of its potential consequences for the selection of the portfolio that, respecting all the constraints, could offer the highest total NPV to the company. With the support of the PROBE software, several measures and scenarios of uncertainty were built in order to reassure the decision-makers about the robustness of the final investment decision. Besides being concerned with the NPV, EDPD also wants to consider other aspects when evaluating the benefits of the projects. A criterion related to environmental impacts of large-scale projects was incorporated in the initial model and a new multicriteria portfolio decision analysis revealed that a small trade-off between NPV and environmental impact could alter the composition of the best portfolio.

Research underway aims at incorporating in the PROBE resource allocation model probabilities associated with uncertain input data, which is particularly relevant in assessing environmental impacts. Besides $N P V$ and environmental impact, quality of service, appraised by the number of consumers' complaints, is currently being considered in a new multicriteria benefit evaluation model. It is important to remark that the PROBE software runs a mono-objective mathematical programming model. A future line of research is the extension of PROBE to consider multiple objective functions, one for each benefit dimension, instead of optimising an aggregated overall benefit. Last but not least, besides the classic approach to address uncertainty on the current mono-objective model, the extension of portfolio decision analysis to the fuzzy methodological framework opens an interesting path for multi-objective allocation of resources, as explored by Ekel et al. (2006, 2008).

\section{Acknowledgements}

The authors thank EDP Distribuição - Energia, S.A., in particular the Head and technical staff of the Department of Network Planning (Direcção de Planeamento de Rede) for their collaboration. J. C. Lourenço and C. A. Bana e Costa acknowledge that their work was supported by the Portuguese national funding agency for science, research and technology (FCT - Fundação para a Ciência e a Tecnologia) under project PTDC/EGE-GES/119230/2010.

\section{References}

Asher, D. T. 1962. A linear programming model for the allocation of R and D efforts, IRE Transactions on Engineering Management 9(4): 154-157. http://dx.doi.org/10.1109/IRET-EM.1962.5007697

Atici, K. B.; Ulucan, A. 2011. A multiple criteria energy decision support system, Technological and Economic Development of Economy 17(2): 219-245. http://dx.doi.org/10.3846/20294913.2011.580563 
Bana e Costa, C. A.; De Corte, J. M.; Vansnick, J. C. 2005. On the mathematical foundations of MACBETH, in J. Figueira, S. Greco, M. Ehrgott (Eds.). Multiple criteria decision analysis: state of the art surveys. Springer, 409-442.

Bana e Costa, C. A.; De Corte, J. M.; Vansnick, J. C. 2012. MACBETH, International Journal of Information Technology \& Decision Making 11(2): 359-387. http://dx.doi.org/10.1142/S0219622012400068

Beaujon, G. J.; Marin, S. P.; McDonald, G. C. 2001. Balancing and optimizing a portfolio of R\&D projects, Naval Research Logistics 48(1): 18-40.

http://dx.doi.org/10.1002/1520-6750(200102)48:1<18::AID-NAV2>3.0.CO;2-7

Brealey, R. A.; Myers, S. C. 2003. Principles of corporate finance. $7^{\text {th }} \mathrm{ed}$. McGraw-Hill/Irwin.

Bryan, B. A. 2010. Development and application of a model for robust, cost-effective investment in natural capital and ecosystem services, Biological Conservation 143(7): 1737-1750.

http://dx.doi.org/10.1016/j.biocon.2010.04.022

Buede, D. M.; Bresnick, T. A. 2007. Applications of decision analysis to the military systems acquisition process, in W. Edwards, R. F. Miles, D. von Winterfeldt (Eds.). Advances in decision analysis: from foundations to applications. Cambridge University Press, 539-563.

Clemen, R. T.; Smith, J. E. 2009. On the choice of baselines in multiattribute portfolio analysis: a cautionary note, Decision Analysis 6(4): 256-262. http://dx.doi.org/10.1287/deca.1090.0158

Dantzig, G. B. 1957. Discrete-variable extremum problems, Operations Research 5(2): 266-277. http://dx.doi.org/10.1287/opre.5.2.266

Dickinson, M. W.; Thornton, A. C.; Graves, S. 2001. Technology portfolio management: optimizing interdependent projects over multiple time periods, IEEE Transactions on Engineering Management 48(4): 518-527. http://dx.doi.org/10.1109/17.969428

Edwards, W. 1977. How to use multiattribute utility measurement for social decisionmaking, IEEE Transactions on Systems, Man and Cybernetics 7(5):326-340. http://dx.doi.org/10.1109/TSMC.1977.4309720

Ekel, P. Ya.; Martini, J. S. C.; Palhares, R. M. 2008. Multicriteria analysis in decision making under information uncertainty, Applied Mathematics and Computation 200(2): 501-516. http://dx.doi.org/10.1016/j.amc.2007.11.024

Ekel, P. Ya.; Martins, C. A. P. S.; Pereira Jr., J. G.; Palhares, R. M.; Canha, L. N. 2006. Fuzzy set based multiobjective allocation of resources and its applications, Computers \& Mathematics with Applications 52(1-2): 197-210. http://dx.doi.org/10.1016/j.camwa.2006.08.013

Ertay, T.; Kahraman, C.; Kaya, İ. 2013. Evaluation of renewable energy alternatives using MACBETH and fuzzy AHP multicriteria methods: the case of Turkey, Technological and Economic Development of Economy 19(1): 38-62. http://dx.doi.org/10.3846/20294913.2012.762950

Ewing, P. L.; Tarantino, W.; Parnell, G. S. 2006. Use of decision analysis in the army base realignment and closure (BRAC) 2005 military value analysis, Decision Analysis 3(1): 33-49. http://dx.doi.org/10.1287/deca.1060.0062

Fasth, T.; Larsson, A. 2013. Sensitivity analysis in portfolio interval decision analysis, in Twenty-sixth International Florida Artificial Intelligence Research Society Conference, 22-24 May 2013, St. Pete Beach, Florida, USA.

Golabi, K. 1987. Selecting a group of dissimilar projects for funding, IEEE Transactions on Engineering Management 34(3): 138-145. http://dx.doi.org/10.1109/TEM.1987.6498874

Gunther, P. 1955. Letter to the editor - use of linear programming in capital budgeting, Journal of the Operations Research Society of America 3(2): 219-224. http://dx.doi.org/10.1287/opre.3.2.219a

Keeney, R. L.; Raiffa, H. 1993. Decisions with multiple objectives: preferences and value tradeoffs. Cambridge University Press. http://dx.doi.org/10.1017/CBO9781139174084

Kleinmuntz, C. E.; Kleinmuntz, D. N. 1999. A strategic approach to allocating capital in healthcare organizations, Healthcare Financial Management 53(4): 52-58. 
Kleinmuntz, D. N. 2007. Resource allocation decisions, in W. Edwards, R. F. Miles, D. von Winterfeldt (Eds.). Advances in decision analysis: from foundations to applications. Cambridge University Press, 400-418.

Liesiö, J.; Mild, P.; Salo, A. 2007. Preference programming for robust portfolio modeling and project selection, European Journal of Operational Research 181(3): 1488-1505. http://dx.doi.org/10.1016/j.ejor.2005.12.041

Liesiö, J.; Mild, P.; Salo, A. 2008. Robust portfolio modeling with incomplete cost information and project interdependencies, European Journal of Operational Research 190(3): 679-695. http://dx.doi.org/10.1016/j.ejor.2007.06.049

Liesiö, J.; Salo, A. 2012. Scenario-based portfolio selection of investment projects with incomplete probability and utility information, European Journal of Operational Research 217(1): 162-172. http://dx.doi.org/10.1016/j.ejor.2011.08.025

Lorie, J. H.; Savage, L. J. 1955. Three problems in rationing capital, The Journal of Business 28(4): 229-239. http://dx.doi.org/10.1086/294081

Lourenço, J. C.; Bana e Costa, C. A.; Morton, A. 2008. Software packages for multi-criteria resource allocation, in IEEE International Engineering Management Conference, IEMC Europe 2008, 28-30 June 2008, Estoril, Portugal. http://dx.doi.org/10.1109/IEMCE.2008.4617948

Lourenço, J. C.; Morton, A.; Bana e Costa, C. A. 2012. PROBE - a multicriteria decision support system for portfolio robustness evaluation, Decision Support Systems 54(1): 534-550. http://dx.doi.org/10.1016/j.dss.2012.08.001

Markowitz, H. M.; Manne, A. S. 1957. On the solution of discrete programming problems, Econometrica 25(1): 84-110. http://dx.doi.org/10.2307/1907744

Morton, A. 2010. On the choice of baselines in portfolio decision analysis [online], Working Paper LSEOR 10.128, London School of Economics, London [cited 23 June 2013]. Available from Internet: http://www2.lse.ac.uk/management/documents/WP-10-128.pdf

Phillips, L. D.; Bana e Costa, C. A. 2007. Transparent prioritisation, budgeting and resource allocation with multi-criteria decision analysis and decision conferencing, Annals of Operations Research 154(1): 51-68. http://dx.doi.org/10.1007/s10479-007-0183-3

Ringuest, J. L.; Graves, S. B. 1990. The linear R\&D project selection problem: an alternative to net present value, IEEE Transactions on Engineering Management 37(2): 143-146. http://dx.doi.org/10.1109/17.53718

Salo, A.; Keisler, J.; Morton, A. (Eds.) 2011a. Portfolio decision analysis: improved methods for resource allocation. Springer. http://dx.doi.org/10.1007/978-1-4419-9943-6

Salo, A.; Keisler, J.; Morton, A. 2011b. An invitation to portfolio decision analysis, in A. Salo, J. Keisler, A. Morton (Eds.). Portfolio decision analysis: improved methods for resource allocation. Springer, 3-28.

Sharpe, P.; Keelin, T. 1998. How Smithkline Beecham makes better resource-allocation decisions, Harvard Business Review 76(2): 45-57.

Stummer, C.; Heidenberger, K. 2003. Interactive R\&D portfolio analysis with project interdependencies and time profiles of multiple objectives, IEEE Transactions on Engineering Management 50(2): 175-183. http://dx.doi.org/10.1109/TEM.2003.810819

Zavadskas, E. K.; Turskis, Z. 2011. Multiple criteria decision making (MCDM) methods in economics: an overview, Technological and Economic Development of Economy 17(2): 397-427. http://dx.doi.org/10.3846/20294913.2011.593291 


\section{APPENDIX}

Table 6. Small-scale projects data (in $€ 10^{3}$ )

\begin{tabular}{|c|c|c|c|c|c|c|c|c|c|}
\hline Project & Zone & $N P V$ & $\begin{array}{l}\text { Cost } \\
\text { on } \\
\text { year } 1\end{array}$ & $\begin{array}{c}\text { Cost } \\
\text { on } \\
\text { year } 2\end{array}$ & Project & Zone & $N P V$ & $\begin{array}{c}\text { Cost } \\
\text { on } \\
\text { year } 1\end{array}$ & $\begin{array}{l}\text { Cost } \\
\text { on } \\
\text { year } 2\end{array}$ \\
\hline 1 & 2 & 3 & 4 & 5 & 6 & 7 & 8 & 9 & 10 \\
\hline P001 & $\mathrm{Z} 1$ & 101.18 & 67.06 & 0 & P036 & $\mathrm{Z} 1$ & 40.81 & 12.86 & 0 \\
\hline P002 & Z1 & 183.02 & 57.69 & 0 & P037 & $\mathrm{Z} 1$ & 35.09 & 12.03 & 0 \\
\hline P003 & $\mathrm{Z} 1$ & 40.19 & 53.98 & 0 & P038 & $\mathrm{Z1}$ & 66.02 & 12 & 0 \\
\hline P004 & Z1 & 0.9 & 14.75 & 0 & P039 & $\mathrm{Z1}$ & 135.43 & 15.74 & 0 \\
\hline P005 & $\mathrm{Z1}$ & 133.21 & 53.97 & 0 & P040 & $\mathrm{Z} 1$ & 18.95 & 10.06 & 0 \\
\hline P006 & $\mathrm{Z1}$ & 124.46 & 14.85 & 26.41 & P041 & $\mathrm{Z} 1$ & 32.25 & 12.07 & 0 \\
\hline P007 & $\mathrm{Z} 1$ & 60.06 & 20.15 & 0 & P042 & $\mathrm{Z} 1$ & 167.1 & 7.75 & 0 \\
\hline P008 & $\mathrm{Z} 1$ & 57.12 & 13.16 & 0 & P043 & $\mathrm{Z} 1$ & 0 & 10.09 & 0 \\
\hline P009 & $\mathrm{Z} 1$ & 1.19 & 38.38 & 0 & P044 & $\mathrm{Z} 1$ & 1.6 & 3.55 & 0 \\
\hline P010 & $\mathrm{Z} 1$ & 142.43 & 37.66 & 0 & P045 & $\mathrm{Z} 2$ & 34.9 & 7.98 & 0 \\
\hline P011 & $\mathrm{Z1}$ & 47.51 & 30.55 & 0 & P046 & $\mathrm{Z} 2$ & 12.27 & 7.16 & 0 \\
\hline P012 & $\mathrm{Z} 1$ & 47.26 & 28.43 & 0 & P047 & $\mathrm{Z} 2$ & 5.29 & 10.57 & 0 \\
\hline $\mathrm{P} 013$ & $\mathrm{Z1}$ & 295.71 & 6.51 & 27 & P048 & $\mathrm{Z} 2$ & 186.84 & 5.21 & 0 \\
\hline P014 & $\mathrm{Z1}$ & 135.42 & 25.04 & 0 & P049 & $\mathrm{Z} 2$ & 3.49 & 22.32 & 0 \\
\hline P015 & $\mathrm{Z1}$ & 94.77 & 24.94 & 0 & P050 & $\mathrm{Z} 2$ & 52.27 & 6.32 & 22.42 \\
\hline P016 & $\mathrm{Z} 1$ & 31.71 & 6.55 & 0 & P051 & $\mathrm{Z} 2$ & 25.19 & 6.58 & 0 \\
\hline P017 & $\mathrm{Z} 1$ & 91.06 & 23 & 0 & P052 & $\mathrm{Z} 2$ & 22.38 & 8.1 & 0 \\
\hline P018 & $\mathrm{Z} 1$ & 53.98 & 23.87 & 1.12 & P053 & $\mathrm{Z} 2$ & 84.94 & 13.51 & 0 \\
\hline P019 & $\mathrm{Z} 1$ & 13.72 & 23.15 & 0 & P054 & $\mathrm{Z} 2$ & 222.7 & 8.4 & 0 \\
\hline P020 & $\mathrm{Z1}$ & 41.76 & 22.98 & 0 & P055 & $\mathrm{Z} 2$ & 18.01 & 4.66 & 0 \\
\hline P021 & $\mathrm{Z1}$ & 0.02 & 10.15 & 0 & P056 & $\mathrm{Z} 2$ & 22.86 & 4.89 & 0 \\
\hline P022 & $\mathrm{Z} 1$ & 1.54 & 2.5 & 0 & P057 & $\mathrm{Z} 2$ & 26.52 & 3.44 & 13.15 \\
\hline P023 & $\mathrm{Z} 1$ & 23.35 & 11.57 & 13.92 & P058 & $\mathrm{Z} 2$ & 2.18 & 1.38 & 0 \\
\hline P024 & $\mathrm{Z} 1$ & 16.61 & 17.55 & 0 & P059 & $\mathrm{Z} 2$ & 0.14 & 3.77 & 5.26 \\
\hline P025 & $\mathrm{Z} 1$ & 8.9 & 15.41 & 0 & P060 & $\mathrm{Z} 2$ & 105.51 & 10.83 & 0 \\
\hline P026 & $\mathrm{Z1}$ & 1.14 & 21.2 & 0 & P061 & $\mathrm{Z} 2$ & 141.47 & 15.42 & 0 \\
\hline P027 & $\mathrm{Z1}$ & 3.31 & 16.65 & 0 & P062 & $\mathrm{Z} 2$ & 77.63 & 15.16 & 0 \\
\hline P028 & $\mathrm{Z1}$ & 47.31 & 21 & 0 & P063 & $\mathrm{Z} 2$ & 0 & 45.45 & 0 \\
\hline P029 & $\mathrm{Z1}$ & 75.59 & 12.66 & 0 & P064 & $\mathrm{Z} 2$ & 184.56 & 18.23 & 0 \\
\hline P030 & $\mathrm{Z} 1$ & 19.58 & 6.84 & 0 & P065 & $\mathrm{Z} 2$ & 52.59 & 11.07 & 0 \\
\hline P031 & $\mathrm{Z1}$ & 3.15 & 3 & 0 & P066 & $\mathrm{Z} 2$ & 91.59 & 5.34 & 0 \\
\hline P032 & $\mathrm{Z1}$ & 73.98 & 14.98 & 0 & P067 & $\mathrm{Z} 2$ & 132.12 & 23.81 & 0 \\
\hline P033 & $\mathrm{Z1}$ & 61.59 & 13.91 & 0 & P068 & $\mathrm{Z} 2$ & 79.06 & 5.01 & 0 \\
\hline P034 & $\mathrm{Z} 1$ & 84.48 & 13.38 & 0 & P069 & $\mathrm{Z} 2$ & 57.92 & 24.67 & 0 \\
\hline P035 & $\mathrm{Z1}$ & 60.59 & 13.28 & 0 & P070 & $\mathrm{Z} 2$ & 121.84 & 10.94 & 0 \\
\hline
\end{tabular}


Continued Table 6

\begin{tabular}{|c|c|c|c|c|c|c|c|c|c|}
\hline 1 & 2 & 3 & 4 & 5 & 6 & 7 & 8 & 9 & 10 \\
\hline P071 & $\mathrm{Z} 2$ & 0.06 & 31.5 & 0 & P110 & $\mathrm{Z} 2$ & 29.48 & 15.5 & 0 \\
\hline P072 & $\mathrm{Z2}$ & 39.57 & 1.67 & 0 & P111 & $\mathrm{Z2}$ & 35.56 & 13.93 & 26.86 \\
\hline P073 & $\mathrm{Z} 2$ & 0.01 & 20.53 & 0 & P112 & $\mathrm{Z} 2$ & 194.79 & 15.41 & 0 \\
\hline P074 & $\mathrm{Z} 2$ & 14.37 & 7.34 & 6.5 & P113 & $\mathrm{Z} 2$ & 119.95 & 14.67 & 0 \\
\hline P075 & $\mathrm{Z} 2$ & 63.39 & 32.23 & 0 & P114 & $\mathrm{Z} 2$ & 24.89 & 14.55 & 0 \\
\hline P076 & $\mathrm{Z2}$ & 123.42 & 39.43 & 0 & P115 & $\mathrm{Z2}$ & 31.98 & 14.44 & 0 \\
\hline P077 & $\mathrm{Z2}$ & 48.81 & 29.75 & 0 & P116 & $\mathrm{Z} 2$ & 204.09 & 22.56 & 0 \\
\hline P078 & $\mathrm{Z2}$ & 34.26 & 38.89 & 0 & P117 & $\mathrm{Z3}$ & 58.39 & 23.1 & 0 \\
\hline P079 & $\mathrm{Z2}$ & 20.93 & 9.75 & 0 & P118 & $\mathrm{Z3}$ & 42.58 & 38.54 & 0 \\
\hline P080 & $\mathrm{Z2}$ & 3.84 & 15.45 & 0 & P119 & $\mathrm{Z3}$ & 58.2 & 30.01 & 0 \\
\hline P081 & $\mathrm{Z} 2$ & 28.83 & 8.04 & 9.25 & P120 & $\mathrm{Z3}$ & 38.37 & 29.95 & 0 \\
\hline P082 & $\mathrm{Z} 2$ & 72.48 & 19.95 & 0 & P121 & $\mathrm{Z3}$ & 62.94 & 27.1 & 0 \\
\hline P083 & $\mathrm{Z2}$ & 165 & 7.33 & 0 & P122 & $\mathrm{Z3}$ & 32.8 & 28.43 & 0 \\
\hline P084 & $\mathrm{Z2}$ & 154.89 & 15.23 & 0 & P123 & $\mathrm{Z3}$ & 60.11 & 32.84 & 0 \\
\hline P085 & $\mathrm{Z} 2$ & 18.52 & 5.26 & 0 & P124 & $\mathrm{Z3}$ & 83.03 & 26.99 & 0 \\
\hline P086 & $\mathrm{Z2}$ & 96.32 & 19.29 & 0 & P125 & $\mathrm{Z3}$ & 362.81 & 23.15 & 0 \\
\hline P087 & $\mathrm{Z2}$ & 11.09 & 9.51 & 7.16 & P126 & $\mathrm{Z3}$ & 271.75 & 23.49 & 0 \\
\hline P088 & $\mathrm{Z2}$ & 45.47 & 34.64 & 0 & P127 & $\mathrm{Z3}$ & 206.07 & 16.93 & 0 \\
\hline P089 & $\mathrm{Z2}$ & 14.07 & 7.29 & 0 & P128 & $\mathrm{Z3}$ & 358.09 & 17.1 & 0 \\
\hline P090 & $\mathrm{Z} 2$ & 0.18 & 6.62 & 10 & P129 & $\mathrm{Z3}$ & 11.42 & 8.93 & 0 \\
\hline P091 & $\mathrm{Z} 2$ & 45.2 & 30.13 & 0 & $\mathrm{P} 130$ & $\mathrm{Z3}$ & 139.51 & 17.7 & 0 \\
\hline P092 & $\mathrm{Z} 2$ & 12.97 & 22.22 & 0 & P131 & $\mathrm{Z3}$ & 6.48 & 3.64 & 0 \\
\hline P093 & $\mathrm{Z} 2$ & 28.85 & 20.25 & 0 & $\mathrm{P} 132$ & $\mathrm{Z3}$ & 253.23 & 15.59 & 1.48 \\
\hline P094 & $\mathrm{Z} 2$ & 72.71 & 10.38 & 0 & P133 & $\mathrm{Z3}$ & 83.6 & 20.96 & 0 \\
\hline P095 & $\mathrm{Z} 2$ & 102.75 & 11.71 & 0 & P134 & $\mathrm{Z3}$ & 153.64 & 36.57 & 0 \\
\hline P096 & $\mathrm{Z} 2$ & 116.23 & 29.11 & 0 & P135 & $\mathrm{Z3}$ & 85.48 & 4.88 & 0 \\
\hline P097 & $\mathrm{Z} 2$ & 63.72 & 23.61 & 0 & P136 & $\mathrm{Z3}$ & 154.34 & 22.83 & 0 \\
\hline P098 & $\mathrm{Z} 2$ & 11 & 80 & 0 & P137 & $\mathrm{Z3}$ & 158.67 & 25.11 & 0 \\
\hline P099 & $\mathrm{Z} 2$ & 80.18 & 20.84 & 0 & P138 & $\mathrm{Z3}$ & 157.15 & 4.27 & 0 \\
\hline P100 & $\mathrm{Z} 2$ & 26.34 & 22.41 & 0 & P139 & $\mathrm{Z3}$ & 124.02 & 8.51 & 0 \\
\hline P101 & $\mathrm{Z} 2$ & 61.38 & 15.42 & 0 & P140 & $\mathrm{Z3}$ & 58.01 & 21.87 & 0 \\
\hline P102 & $\mathrm{Z} 2$ & 34.8 & 16.74 & 0 & P141 & $\mathrm{Z3}$ & 117.88 & 5.6 & 0 \\
\hline P103 & $\mathrm{Z} 2$ & 12.43 & 4.85 & 0 & $\mathrm{P} 142$ & $\mathrm{Z3}$ & 299.01 & 26.68 & 0 \\
\hline P104 & $\mathrm{Z} 2$ & 64.3 & 27.4 & 0 & P143 & $\mathrm{Z3}$ & 23.35 & 6.85 & 0 \\
\hline P105 & $\mathrm{Z} 2$ & 115.98 & 17.55 & 0 & P144 & $\mathrm{Z3}$ & 318.5 & 23.58 & 0 \\
\hline P106 & $\mathrm{Z} 2$ & 57.76 & 16.88 & 0 & P145 & $\mathrm{Z3}$ & 47.21 & 6.69 & 0 \\
\hline P107 & $\mathrm{Z} 2$ & 5.11 & 20.3 & 0 & P146 & $\mathrm{Z3}$ & 117.57 & 2.97 & 0 \\
\hline P108 & $\mathrm{Z} 2$ & 26.03 & 9.82 & 0 & P147 & $\mathrm{Z3}$ & 94.29 & 11.59 & 0 \\
\hline P109 & $\mathrm{Z} 2$ & 38.05 & 15.65 & 0 & P148 & $\mathrm{Z3}$ & 26.28 & 8.94 & 0 \\
\hline
\end{tabular}


Continued Table 6

\begin{tabular}{|c|c|c|c|c|c|c|c|c|c|}
\hline 1 & 2 & 3 & 4 & 5 & 6 & 7 & 8 & 9 & 10 \\
\hline P149 & $\mathrm{Z3}$ & 88.9 & 9.8 & 0 & P188 & $\mathrm{Z3}$ & 73.05 & 25.68 & 0 \\
\hline P150 & $\mathrm{Z3}$ & 172.81 & 30.36 & 0 & P189 & $\mathrm{Z3}$ & 72.71 & 22.85 & 0 \\
\hline P151 & $\mathrm{Z3}$ & 122.14 & 8.42 & 0 & P190 & $\mathrm{Z3}$ & 95.22 & 19.3 & 0 \\
\hline P152 & $\mathrm{Z3}$ & 123.92 & 5.91 & 0 & P191 & $\mathrm{Z3}$ & 125.8 & 22.1 & 0 \\
\hline P153 & $\mathrm{Z3}$ & 38.48 & 7.9 & 0 & P192 & $\mathrm{Z3}$ & 70.54 & 32.7 & 0 \\
\hline P154 & $\mathrm{Z3}$ & 54.98 & 8.09 & 0 & P193 & $\mathrm{Z3}$ & 159.37 & 9.11 & 0 \\
\hline P155 & $\mathrm{Z3}$ & 144.53 & 26.96 & 0 & P194 & $\mathrm{Z3}$ & 62.25 & 26.92 & 0 \\
\hline P156 & $\mathrm{Z3}$ & 204.29 & 14.56 & 0 & P195 & $\mathrm{Z3}$ & 4.2 & 23.32 & 0 \\
\hline P157 & $\mathrm{Z3}$ & 72.65 & 3.05 & 0 & P196 & $\mathrm{Z3}$ & 81.28 & 16.26 & 25.97 \\
\hline $\mathrm{P} 158$ & $\mathrm{Z3}$ & 69.86 & 8.65 & 0 & P197 & $\mathrm{Z3}$ & 45.54 & 26.6 & 0 \\
\hline P159 & $\mathrm{Z3}$ & 42.37 & 4.14 & 0 & P198 & $\mathrm{Z3}$ & 0.82 & 18.85 & 0 \\
\hline P160 & $\mathrm{Z3}$ & 28.94 & 20.68 & 0 & P199 & $\mathrm{Z3}$ & 14.3 & 6.78 & 0 \\
\hline P161 & $\mathrm{Z3}$ & 33.07 & 15.4 & 0 & P200 & $\mathrm{Z4}$ & 216.29 & 24.84 & 0 \\
\hline P162 & $\mathrm{Z3}$ & 41.04 & 6.77 & 4.46 & P201 & $\mathrm{Z} 4$ & 35.78 & 34.7 & 0 \\
\hline P163 & $\mathrm{Z3}$ & 9.86 & 3.65 & 0 & P202 & $\mathrm{Z} 4$ & 59.41 & 13.54 & 0 \\
\hline P164 & $\mathrm{Z3}$ & 27.9 & 3.89 & 0 & P203 & $\mathrm{Z4}$ & 24.54 & 31.76 & 0 \\
\hline P165 & $\mathrm{Z3}$ & 71.07 & 12.39 & 0 & P204 & $\mathrm{Z} 4$ & 49.69 & 17.93 & 0 \\
\hline P166 & $\mathrm{Z3}$ & 0.43 & 30.29 & 1.95 & P205 & $\mathrm{Z} 4$ & 76.68 & 16.06 & 0 \\
\hline P167 & $\mathrm{Z3}$ & 41.23 & 13.67 & 0 & P206 & $\mathrm{Z4}$ & 3.83 & 24.3 & 0 \\
\hline P168 & $\mathrm{Z3}$ & 108.87 & 34.96 & 0 & P207 & $\mathrm{Z} 4$ & 12.92 & 21.07 & 0 \\
\hline P169 & $\mathrm{Z3}$ & 36.86 & 17.07 & 0 & P208 & $\mathrm{Z} 4$ & 74.53 & 14.16 & 0.74 \\
\hline $\mathrm{P} 170$ & $\mathrm{Z3}$ & 49.46 & 23.93 & 2.68 & P209 & $\mathrm{Z} 4$ & 14.91 & 4.25 & 0 \\
\hline $\mathrm{P} 171$ & $\mathrm{Z3}$ & 74.83 & 37.52 & 0 & $\mathrm{P} 210$ & $\mathrm{Z} 4$ & 17.51 & 4.6 & 0 \\
\hline $\mathrm{P} 172$ & $\mathrm{Z3}$ & 81.22 & 22.89 & 0 & P211 & $\mathrm{Z} 4$ & 66.16 & 13.66 & 0 \\
\hline P173 & $\mathrm{Z3}$ & 30.6 & 20.92 & 0 & $\mathrm{P} 212$ & $\mathrm{Z} 4$ & 51.18 & 14.52 & 12.94 \\
\hline P174 & $\mathrm{Z3}$ & 158.4 & 4.51 & 0 & P213 & $\mathrm{Z} 4$ & 83.51 & 15.99 & 0 \\
\hline P175 & $\mathrm{Z3}$ & 28.92 & 4.02 & 0 & P214 & $\mathrm{Z} 4$ & 148.52 & 6.56 & 0 \\
\hline P176 & $\mathrm{Z3}$ & 44.86 & 2.73 & 0 & P215 & $\mathrm{Z} 4$ & 30.53 & 10.2 & 0 \\
\hline P177 & $\mathrm{Z3}$ & 16.85 & 8.1 & 0 & $\mathrm{P} 216$ & $\mathrm{Z} 4$ & 35.65 & 11.11 & 7.75 \\
\hline P178 & $\mathrm{Z3}$ & 60.83 & 5.14 & 0 & P217 & $\mathrm{Z} 4$ & 0.1 & 10.26 & 18.67 \\
\hline P179 & $\mathrm{Z3}$ & 104.88 & 6.23 & 0 & P218 & $\mathrm{Z} 4$ & 37.76 & 15.04 & 8.42 \\
\hline $\mathrm{P} 180$ & $\mathrm{Z3}$ & 56.07 & 4.08 & 0 & P219 & $\mathrm{Z} 5$ & 8.24 & 9.43 & 13.16 \\
\hline P181 & $\mathrm{Z3}$ & 237.64 & 22.92 & 0 & P220 & $\mathrm{Z} 5$ & 0.4 & 3.66 & 0 \\
\hline P182 & $\mathrm{Z3}$ & 63.31 & 17.13 & 0 & P221 & $\mathrm{Z} 5$ & 35.08 & 13.11 & 2.16 \\
\hline P183 & $\mathrm{Z3}$ & 184.58 & 32.78 & 0 & P222 & $\mathrm{Z} 5$ & 56 & 13.56 & 0 \\
\hline P184 & $\mathrm{Z3}$ & 94.47 & 16.16 & 0 & P223 & $\mathrm{Z} 5$ & 8.41 & 4 & 0 \\
\hline P185 & $\mathrm{Z3}$ & 127.9 & 13.41 & 0 & P224 & $\mathrm{Z} 5$ & 55.74 & 3.95 & 0 \\
\hline P186 & $\mathrm{Z3}$ & 34.16 & 27.32 & 0 & P225 & $\mathrm{Z} 5$ & 6.49 & 5.17 & 0 \\
\hline P187 & $\mathrm{Z3}$ & 83.04 & 22.02 & 0 & P226 & $\mathrm{Z} 5$ & 19.9 & 13.33 & 0 \\
\hline
\end{tabular}


Continued Table 6

\begin{tabular}{|c|c|c|c|c|c|c|c|c|c|}
\hline 1 & 2 & 3 & 4 & 5 & 6 & 7 & 8 & 9 & 10 \\
\hline P227 & $\mathrm{Z} 5$ & 22.8 & 5.61 & 23.78 & P266 & Z5 & 18.52 & 41.86 & 0 \\
\hline P228 & $\mathrm{Z} 5$ & 62.67 & 10.05 & 0 & P267 & $\mathrm{Z5}$ & 14.72 & 33.91 & 0 \\
\hline P229 & $\mathrm{Z} 5$ & 29.08 & 11.76 & 0 & P268 & Z5 & 111.87 & 16 & 0 \\
\hline P230 & $\mathrm{Z} 5$ & 30.27 & 2.46 & 0 & P269 & $\mathrm{Z5}$ & 76.76 & 20.2 & 1.12 \\
\hline P231 & $\mathrm{Z5}$ & 105.71 & 22.18 & 0 & P270 & $\mathrm{Z5}$ & 17.58 & 24.13 & 0 \\
\hline $\mathrm{P} 232$ & $\mathrm{Z} 5$ & 14.23 & 4.29 & 0 & P271 & $\mathrm{Z5}$ & 73.73 & 6.51 & 14.58 \\
\hline P233 & $\mathrm{Z} 5$ & 11.16 & 10.76 & 0 & P272 & $\mathrm{Z5}$ & 58.97 & 20.34 & 0 \\
\hline P234 & $\mathrm{Z5}$ & 1.95 & 20 & 0 & P273 & $\mathrm{Z5}$ & 98.3 & 18.27 & 0 \\
\hline P235 & $\mathrm{Z} 5$ & 2.44 & 26.59 & 0 & P274 & $\mathrm{Z5}$ & 0.86 & 28.5 & 0 \\
\hline P236 & $\mathrm{Z5}$ & 38.13 & 25.19 & 0 & P275 & $\mathrm{Z5}$ & 6.71 & 18.7 & 0 \\
\hline P237 & $\mathrm{Z} 5$ & 0.96 & 19.95 & 0 & P276 & $\mathrm{Z5}$ & 3.74 & 20.64 & 5.91 \\
\hline P238 & $\mathrm{Z} 5$ & 39.64 & 25.43 & 0 & P277 & $\mathrm{Z} 5$ & 5.3 & 11.77 & 0 \\
\hline P239 & $\mathrm{Z5}$ & 44.83 & 11.62 & 0 & P278 & $\mathrm{Z5}$ & 176.73 & 37.75 & 0 \\
\hline P240 & $\mathrm{Z} 5$ & 7.34 & 34.83 & 0 & P279 & $\mathrm{Z5}$ & 327.91 & 13.12 & 0 \\
\hline P241 & $\mathrm{Z5}$ & 18.97 & 12.25 & 0 & P280 & $\mathrm{Z} 5$ & 17.48 & 4.82 & 0 \\
\hline P242 & $\mathrm{Z5}$ & 206.61 & 17.01 & 0 & P281 & $\mathrm{Z5}$ & 58.16 & 26.03 & 0 \\
\hline P243 & $\mathrm{Z5}$ & 97.81 & 9.17 & 0 & P282 & $\mathrm{Z5}$ & 31.86 & 45.28 & 0 \\
\hline P244 & $\mathrm{Z5}$ & 43.69 & 6.35 & 0 & P283 & $\mathrm{Z} 5$ & 142.9 & 17.54 & 0 \\
\hline P245 & $\mathrm{Z5}$ & 155.52 & 51.15 & 0 & P284 & $\mathrm{Z5}$ & 58.36 & 12.07 & 0 \\
\hline P246 & $\mathrm{Z5}$ & 85.43 & 5.32 & 0 & P285 & $\mathrm{Z5}$ & 105.57 & 27.42 & 0 \\
\hline P247 & $\mathrm{Z5}$ & 156.27 & 12.3 & 0.03 & P286 & $\mathrm{Z} 5$ & 291.64 & 34.4 & 0 \\
\hline P248 & $\mathrm{Z5}$ & 48.79 & 20.93 & 0 & P287 & $\mathrm{Z} 5$ & 43.43 & 14.54 & 0 \\
\hline P249 & $\mathrm{Z} 5$ & 77.82 & 8.63 & 0 & P288 & $\mathrm{Z} 5$ & 40.1 & 14.91 & 0 \\
\hline P250 & $\mathrm{Z5}$ & 286.17 & 100.89 & 0 & P289 & $\mathrm{Z} 5$ & 115.91 & 7.95 & 0 \\
\hline P251 & $\mathrm{Z5}$ & 34.79 & 20.3 & 5.29 & P290 & $\mathrm{Z} 5$ & 42.27 & 8.74 & 0 \\
\hline $\mathrm{P} 252$ & $\mathrm{Z5}$ & 64.72 & 8.05 & 0 & P291 & $\mathrm{Z} 5$ & 15.73 & 14.24 & 0 \\
\hline P253 & $\mathrm{Z5}$ & 39.02 & 11.76 & 0 & P292 & $\mathrm{Z} 5$ & 43.85 & 3.54 & 0 \\
\hline P254 & $\mathrm{Z5}$ & 19.01 & 31.67 & 0 & P293 & $\mathrm{Z} 5$ & 183.72 & 14.66 & 2.93 \\
\hline P255 & $\mathrm{Z5}$ & 288.59 & 16.29 & 0 & P294 & Z6 & 42.45 & 41.36 & 0 \\
\hline P256 & $\mathrm{Z5}$ & 71.18 & 16.34 & 0 & P295 & Z6 & 9.94 & 13.84 & 0 \\
\hline P257 & $\mathrm{Z5}$ & 81.61 & 11.03 & 0 & P296 & Z6 & 30.9 & 28.67 & 0 \\
\hline P258 & $\mathrm{Z5}$ & 43.25 & 17.38 & 0 & P297 & Z6 & 43.78 & 31.22 & 0 \\
\hline P259 & $\mathrm{Z5}$ & 281.03 & 21.32 & 0 & P298 & Z6 & 1.47 & 18.39 & 0 \\
\hline P260 & $\mathrm{Z5}$ & 96.18 & 31.2 & 0 & P299 & Z6 & 25.18 & 15.63 & 0 \\
\hline P261 & $\mathrm{Z} 5$ & 27.31 & 31.51 & 0 & P300 & Z6 & 40.47 & 15.46 & 0 \\
\hline P262 & $\mathrm{Z5}$ & 68.91 & 18.14 & 0 & P301 & Z6 & 2.6 & 22.11 & 0 \\
\hline P263 & $\mathrm{Z5}$ & 55.67 & 20.77 & 0 & P302 & Z6 & 26.59 & 12.25 & 0 \\
\hline P264 & $\mathrm{Z5}$ & 212.9 & 25.79 & 0 & P303 & Z6 & 0.76 & 5.6 & 0 \\
\hline P265 & $\mathrm{Z5}$ & 146.96 & 26.26 & 0 & P304 & $\mathrm{Z6}$ & 53.85 & 19.4 & 0 \\
\hline
\end{tabular}


End of Table 6

\begin{tabular}{cccccccccc}
\hline 1 & 2 & 3 & 4 & 5 & 6 & 7 & 8 & 9 & 10 \\
\hline P305 & Z6 & 105.63 & 20.91 & 0 & P325 & Z6 & 13.2 & 15.06 & 0 \\
\hline P306 & Z6 & 81.56 & 23.84 & 0 & P326 & Z6 & 79.24 & 58.38 & 0 \\
\hline P307 & Z6 & 24.06 & 8.77 & 0 & P327 & Z6 & 20.36 & 3.13 & 0 \\
\hline P308 & Z6 & 9.07 & 13.93 & 0 & P328 & Z6 & 0.01 & 20.05 & 0 \\
\hline P309 & Z6 & 57.73 & 7.91 & 0 & P329 & Z6 & 0.1 & 20.44 & 0 \\
\hline P310 & Z6 & 6.76 & 6.06 & 0 & P330 & Z6 & 35.58 & 6.36 & 0 \\
\hline P311 & Z6 & 20.29 & 15.05 & 0 & P331 & Z6 & 114.28 & 22.88 & 0 \\
\hline P312 & Z6 & 40.79 & 9.3 & 0 & P332 & Z6 & 275.55 & 9.07 & 0 \\
\hline P313 & Z6 & 31.12 & 5.57 & 0 & P333 & Z6 & 56.18 & 19.12 & 0.23 \\
\hline P314 & Z6 & 79.53 & 15.2 & 0 & P334 & Z6 & 26.85 & 8.49 & 0 \\
\hline P315 & Z6 & 77.72 & 22.98 & 0 & P335 & Z6 & 76.74 & 13.42 & 0 \\
\hline P316 & Z6 & 50.53 & 11.61 & 17.01 & P336 & Z6 & 83.96 & 8.21 & 0 \\
\hline P317 & Z6 & 41.31 & 20.25 & 0 & P337 & Z6 & 212 & 6.94 & 21.75 \\
\hline P318 & Z6 & 88.72 & 10.45 & 0 & P338 & Z6 & 124.89 & 36.82 & 0 \\
\hline P319 & Z6 & 89.51 & 20.01 & 0 & P339 & Z6 & 98.32 & 19.9 & 0 \\
\hline P320 & Z6 & 103.52 & 8.99 & 0 & P340 & Z6 & 83.72 & 25.69 & 0 \\
\hline P321 & Z6 & 109.16 & 15.7 & 0 & P341 & Z6 & 119.5 & 8.45 & 0 \\
\hline P322 & Z6 & 117.24 & 19.1 & 0 & P342 & Z6 & 30.16 & 17.6 & 0 \\
\hline P323 & Z6 & 149.28 & 6.65 & 14.38 & P343 & Z6 & 0.01 & 11.13 & 0 \\
\hline P324 & Z6 & 43.81 & 13.42 & 0 & P344 & Z6 & 14.8 & 101.58 & 0 \\
\hline
\end{tabular}

Table 7. NPV scores, $E I$ scores and annual costs $\left(\right.$ in $€ 10^{3}$ ) of the large-scale projects

\begin{tabular}{cccccc}
\hline Project & $N P V$ score & EI score & Cost on year 1 & Cost on year 2 & Cost on year 3 \\
\hline 1 & 2 & 3 & 4 & 5 & 6 \\
\hline P01 & 3.88 & -62.5 & 27.64 & 559.49 & 0 \\
\hline P02 & 2.48 & 0 & 126 & 0 & 0 \\
\hline P03 & 125.20 & -62.5 & 268.78 & 1800 & 1.615 \\
\hline P04 & 49.90 & 0 & 2372.47 & 2591.65 & 0 \\
\hline P05 & 190.20 & 0 & 997.95 & 553.67 & 3669.78 \\
\hline P06 & 38.75 & 0 & 3205.39 & 169.18 & 10 \\
\hline P07 & 24.46 & 0 & 3239.98 & 288.14 & 0 \\
\hline P08 & 9.16 & -62.5 & 2466.87 & 431.62 & 4.04 \\
\hline P09 & 12.21 & -62.5 & 319.88 & 1468.61 & 0 \\
\hline P10 & 200.28 & -37.5 & 545.53 & 56.85 & 0 \\
\hline P11 & 3.67 & 0 & 69.57 & 105 & 0 \\
\hline P12 & 8.12 & 0 & 1189.53 & 129.18 & 0 \\
\hline P13 & 28.92 & 0 & 1373.22 & 739.45 & 0 \\
\hline P14 & 6.85 & -37.5 & 299.82 & 7 & 0 \\
\hline P15 & 190.78 & 0 & 1587.36 & 436.12 & 400 \\
\hline P16 & 162.36 & -37.5 & 300 & & 0 \\
\hline
\end{tabular}


End of Table 7

\begin{tabular}{cccccc}
\hline 1 & 2 & 3 & 4 & 5 & 6 \\
\hline P17 & 162.36 & -37.5 & 648.38 & 1125.45 & 0 \\
\hline P18 & 99.52 & 0 & 696.08 & 1430 & 1018.46 \\
\hline P19 & 136.35 & -37.5 & 2605.13 & 2770.27 & 0 \\
\hline P20 & 0.01 & 0 & 2033.12 & 1872.21 & 0 \\
\hline P21 & 7.77 & -37.5 & 2066.03 & 416.59 & 0 \\
\hline P22 & 8.93 & -37.5 & 35.49 & 3048.74 & 0 \\
\hline P23 & 64.94 & 0 & 839.78 & 596.33 & 0 \\
\hline P24 & 0.02 & -37.5 & 3070.71 & 382.23 & 0 \\
\hline P25 & 0.02 & -37.5 & 550.03 & 649.65 & 0 \\
\hline P26 & 0.02 & -100 & 907.09 & 1007.67 & 0 \\
\hline P27 & 14.98 & -37.5 & 1280.18 & 757.59 & 4192.11 \\
\hline P28 & 8.48 & 0 & 225 & 100 & 1225 \\
\hline
\end{tabular}

João Carlos LOURENÇO. He has a PhD in Industrial Engineering and Management. He is Assistant Professor at the Department of Engineering and Management of Instituto Superior Técnico (IST), Universidade de Lisboa, and member of the research staff of CEG-IST, the Centre for Management Studies of IST. His main publications and research interests include decision analysis, portfolio decision analysis, decision support systems, operational research, and sustainability.

João Oliveira SOARES. He is Associate Professor of Economics and Finance at the Department of Engineering and Management of Instituto Superior Técnico (IST), Universidade de Lisboa, and member of the research staff of CEG-IST, the Centre for Management Studies of IST. He is a Portuguese economist with a PhD in Industrial Engineering and Management, and Habilitation in Management. His main publications and research interests cover a variety of issues on capital budgeting, financial analysis, multivariate statistics, and regional development and tourism.

Carlos A. BANA E COSTA (http://web.tecnico.ulisboa.pt/carlosbana). He is Professor of Decision Sciences at the Instituto Superior Técnico (IST), Universidade de Lisboa. He is member of the research staff of CEG-IST, the Centre for Management Studies of IST and co-author of the MACBETH approach for multi-criteria value measurement (http://www.m-macbeth.com). He is also a senior partner of BANA Consulting (http://www.bana-consulting.pt). 